\title{
Unacceptable face of private practice: prescription of controlled drugs to addicts
}

\author{
THOMAS BEWLEY, A HAMID GHODSE
}

\begin{abstract}
Self administered questionnaires completed by 69 out of 100 consecutive drug addicts attending two drug dependence clinics suggested that some private general practitioners were easily persuaded to prescribe controlled drugs. These drugs were usually methadone, dipipanone-cyclizine (Diconal), and methylphenidate (Ritalin). Numbers of new narcotic addicts notified to the Home Office confirmed the practice, which may lead to a severe spread of addiction, as occurred in the $1960 \mathrm{~s}$ with heroin and cocaine.

If the General Medical Council or a tribunal set up in accordance with the Misuse of Drugs Act 1971 cannot stop the practice, then the present licensing system should be extended to include all controlled drugs.
\end{abstract}

\section{Introduction}

Prescribing drugs of addiction to addicts is accepted medical practice in Britain, ${ }^{1-4}$ controlled studies suggesting measurable benefits for patients. ${ }^{5-7}$ The first report of the Brain committee ${ }^{2}$ stated that addiction should be regarded as an extension of mental disorder, rather than a form of criminal behaviour. The committee also accepted that "a person may be able to lead a reasonably satisfactory life on a small and regular dose of a narcotic drug." The second report ${ }^{3}$ concluded that the major source of supply (of drugs to addicts) resulted from the activity of a very few doctors who had prescribed excessively. In the 1960s the main drugs prescribed to addicts were heroin and cocaine, and the committee recommended that the prescribing of heroin and cocaine to addicts should be strictly limited to doctors at special drug treatment centres, and that it should be made illegal for other doctors to prescribe these drugs to an addict. Disciplinary procedures were recommended for doctors found to have prescribed heroin and cocaine irregularly to addicts and it was further recommended that such procedures should be the responsibility of the General Medical Council.

In 1968 the regulations governing supplies to addicts under the Dangerous Drugs Act 1967 came into operation. All addicts who were having heroin or cocaine prescribed for them by general or private practitioners were transferred to new treatment clinics staffed by doctors with licenses to prescribe. Controls on prescribing heroin and cocaine were continued in the Misuse of Drugs Act $1971,{ }^{8}$ and subsequently there was virtually no prescribing to addicts by other than licensed

St Thomas's and Tooting Bec Hospitals, London

THOMAS BEWLEY, FRCPSYCH, FRCPI, consultant psychiatrist

St George's and Tooting Bec Hospitals, London

A HAMID GHODSE, PHD, MRCPSYCH, consultant psychiatrist

Correspondence to: Dr Thomas Bewley, Tooting Bec Hospital, London SW $178 \mathrm{BL}$ practitioners. In the past three years, however, the pattern has shown a pronounced change (table), large numbers of addicts again having drugs prescribed for them by private general practitioners. These drugs are no longer heroin and cocaine but other controlled drugs which are not included in the licensing regulations.

New narcotic addicts notified to Home Office

\begin{tabular}{ccccc}
\hline & \multicolumn{3}{c}{ Source of notification } & \\
\cline { 2 - 4 } Year & $\begin{array}{c}\text { Hospital treatment } \\
\text { centre } \dagger\end{array}$ & $\begin{array}{c}\text { Prison medical } \\
\text { officer }\end{array}$ & $\begin{array}{c}\text { General medical } \\
\text { practitioner }\end{array}$ & Total \\
\hline 1972 & 480 & 250 & 80 & 800 \\
1973 & 430 & 230 & 150 & 807 \\
1974 & 380 & 240 & 250 & 870 \\
1975 & 390 & 270 & 260 & 922 \\
1976 & 400 & 290 & 370 & 1109 \\
1977 & 450 & 290 & 720 & 1347 \\
1978 & 590 & 270 & 720 & 1597 \\
1979 & 610 & 240 & 790 & 1600 \\
1980 & 570 & 320 & 1220 & 2300 \\
$1981^{*}$ & 760 & & &
\end{tabular}

*Provisional.

†Estimated breakdown: numbers rounded independently, so may not add to total shown.

(Data from Hansard."

The reasons for such large numbers of addicts attending private practitioners may be that these doctors prescribe larger doses of drugs, prescribe central nervous stimulants, and prescribe drugs for injection. The opiate Diconal (dipipanone and cyclizine), which is not controlled under the licensing regulations, is widely prescribed to addicts in tablet form, despite the fact that addicts crush the tablets for self injection. Methylphenidate (Ritalin), a central nervous system stimulant, is also widely prescribed, although the only generally accepted medical indications for its use are in narcolepsy and for hyperkinetic children. ${ }^{9}$

There are differences in prescribing practices between doctors in National Health Service clinics and private practitioners. Hospital doctors do not work single handed and in isolation but have the backing of a multidisciplinary team, have access to other NHS facilities such as toxicological analysis, and can thus prescribe more objectively. Some private practitioners 10 believed that their prescribing "freed addicts from the pedlars and other black market activities." Another practitioner ${ }^{11}$ asked why addicts did not go to clinics, noting the expense of obtaining drugs in the black market. The explanation that giving large amounts of drugs to addicts who might then sell them in the black market was not considered. Precautions to be taken when prescribing controlled drugs for addicts have been outlined $^{12}$ and assessment procedures described ${ }^{13}$; regrettably, these are apparently seldom observed by some practitioners.

In order to find out more about the recent changes we asked patients attending the outpatient clinics at St Thomas's and St George's Hospitals for their views about private prescribing of drugs. We also reviewed some of the case records of patients who had left the clinics to go to private practitioners. 


\section{Method}

We gave a self administered questionnaire to 100 consecutive patients attending two drug dependence treatment clinics to obtain their views of private prescribing of controlled drugs. The questionnaires were completed anonymously. A summary of the case notes of nine patients are presented as examples of some of the problems and types of prescribing practice encountered in the preceding year.

\section{Results}

\section{PITIENTS' VIEWS}

Sixty nine of the 100 questionnaires were completed. Not all respondents answered every question. Half of the respondents had attended a private practitioner on some occasion.

The reasons given why addicts went to private doctors were: they prescribe injectable drugs (44 out of 48 respondents); they prescribe more than one drug (38 out of 40 respondents); they give prescriptions which can be dispensed once a week (36 out of 39 respondents); they prescribe what is asked for (51 out of 56 respondents); they prescribe larger doses (36 out of 40 respondents); they have not all the clinics' regulations (37 out of 41 respondents); they treat addicts better (16 out of 38 respondents). Fifty of the 69 addicts generally considered that private doctors were more easily conned than clinic doctors. Out of 44 patients who answered this specific question, 37 found it easier to get a prescription from a private doctor than a clinic doctor; and 31 out of 39 stated that some private doctors in effect sold drugs for money. Forty two out of 45 patients stated that addicts attending private practitioners sold some of the drugs prescribed to pay the chemist's prescribing fee or doctor's bill.

\section{CASE HISTORIES}

The following nine patients from the two clinics had attended private practitioners at some time.

Case 1-This man had been attending regularly for treatment and then stopped attending without notice. He had gone to a private practitioner, who did not check that he was already receiving treatment and having a prescription for an opiate. He was given a prescription for ampoules of injectable methadone. Within a week he was arrested for selling methadone ampoules and is still in jail.

Case 2-A man and his wife (case 3) had been attending a clinic for 11 and six years respectively because of their problems of dependence on opiates, central nervous system stimulants, and barbiturates. They had improved considerably and for two years had apparently not used illicit drugs. They were both having a prescription for methadone. The husband went to a private practitioner, who did not check on his previous and present treatments and gave him further prescriptions for Diconal and Ritalin. These drugs were crushed and taken by injection by both patients, the wife developing septicaemia.

Case 4-This patient attended a private practitioner, who contacted the drug dependence clinic for information about the patient (who had inquired about switching to a private doctor). An account of the patient's history and current treatment was sent to this doctor, who took him on despite the fact that the patient had no financial resources and was living on supplementary benefit.

Case 5-This woman had had bacterial endocarditis as a result of a contaminated self injection. Subsequently her medication had been changed to oral methadone. She later visited a private practitioner, who gave her prescriptions for injectable drugs without consultation with any of the doctors who had been concerned in her treatment-her general practitioner, the clinic staff, and the staff of the hospital where she had been treated for endocarditis.

Case 6-A man had attended a clinic for many years interspersed with periods in prison. On one occasion after leaving prison he went to a private practitioner, who prescribed $140(10 \mathrm{mg})$ ampoules of methadone (black market value $£ 700$ ) to be dispensed at fortnightly intervals. Another man (case 7) was admitted to a general hospital with thrombophlebitis in both legs. He gave his name as that of case 6 , volunteering that he picked up 140 ampoules of methadone fortnightly at a named chemist. The chemist confirmed that the ampoules had been dispensed at the stated time. The masquerade was later discovered, and the hospital doctor was left with a strong impression that the patient regularly bought his supply of drugs from case 6 .

Case 8 -This patient was stabilised on methadone $40 \mathrm{mg}$ by mouth daily. After losing his job he went to a private practitioner and received a prescription for $700 \mathrm{mg}$ methadone, 140 Diconal tablets, and 140 Ritalin tablets to be dispensed fortnightly. He took all the Diconal and part of the Ritalin himself and sold the rest. He developed a psychosis that necessitated admission to hospital, having caused considerable disturbance to his family and neighbours. His doctor was informed but nevertheless resumed the prescription for the same drugs in the same dosage immediately the patient was discharged from hospital.

Case 9-A man was receiving $100 \mathrm{mg}$ methadone (ampoules $60 \mathrm{mg}$, mixture $40 \mathrm{mg}$ ), two Ritalin tablets, and $40 \mathrm{mg}$ diazepam daily from a private doctor. After release from prison (three weeks in custody charged with selling drugs) he telephoned the doctor and made an appointment for one week later. He collected a prescription for the interim period from the secretary for methadone in the same dose as before. While in prison, however, he had been withdrawn from drugs and had lost some of his tolerance to opiates. He suffered a serious overdose necessitating four days in an intensive care unit when he took the drugs which had been prescribed for him.

\section{Discussion}

In the 1960 s uncontrolled prescribing by private practitioners led to a severe spread of addiction. This stopped when controls were introduced, but these were imposed only on heroin and cocaine. There is evidence that there has again been an increase in private prescribing of controlled drugs to addicts by private practitioners. The situation is similar to the 1960 s except that the drugs now being prescribed unduly liberally are methadone, Diconal, and Ritalin. There is an urgent need to control prescribing of this type. Also it is questionable whether it is ever desirable to prescribe controlled drugs to an addict when a fee is paid.

We estimate that a doctor could receive over $£ 100000$ a year solely by prescribing controlled drugs to addicts (by writing 20 prescriptions daily). Addicts have to pay the full cost of privately prescribed drugs as well as the chemist's dispensing fee and the doctor's fee. Some of them sell some of their drugs (from the Harley Street and Piccadilly Circus Golden Triangle) to get the funds to do this. If neither the General Medical Council nor a tribunal constituted for this purpose in accordance with section 14 of the Misuse of Drugs Act 1971 can stop these practices, then extension of the present licensing system to include all controlled drugs, as recommended by the Advisory Council on the Misuse of Drugs, is probably the only way that this can be achieved.

\section{References}

${ }^{1}$ Ministry of Health. Report of Departmental Committee on Morphine and Heroin Addiction. London: HMSO, 1926. (Chairman Sir H Rolleston.)

2 Ministry of Health. Department of Health for Scotland. Drug addiction: report of inter-departmental committee. London: HMSO, 1961. (Chairman Lord Brain.)

${ }^{3}$ Ministry of Health. Department of Health for Scotland. Drug addiction: second report of inter-departmental committee. London: HMSO, 1965. (Chairman Lord Brain.)

${ }^{4}$ Department of Health and Social Security. Treatment and rehabilitation. Report of the Advisory Council on the Misuse of Drugs. London: HMSO, 1982.

${ }^{5}$ McGlothlin WH, Anglin MD. Long-term follow-up of clients of highand-low dose methadone programs. Arch Gen Psychiatry 1981;38: 1055-63.

${ }^{6}$ Newman RG, Whitehill WB. Double-blind comparison of methadone and placebo maintenance treatments of narcotic addicts in Hong Kong. Lancet $1979 ;$ ii :485-8.

7 Sells SB, Simpson DD. The case for drug abuse treatment effectiveness, based on the DARP research program. Brf Addict 1980;2:117-31.

' Her Majesty's Government. Misuse of drugs act 1971. London: HMSO, 1971.

${ }^{9}$ British Medical Association and The Pharmaceutical Society of Great Britain. Central nervous system stimulants. British National Formulary Number 4 (1982). London: BMA and PSGB, 1982:138.

${ }^{10}$ Frankau IM, Stanwell PM. The treatment of drug addiction. Lancet $1960 ;$ ii : $1377-9$.

11 Dally A. Have drug clinics failed? Sunday Times 1983;February 27: p 18 columns 5-7.

12. Bewley TH. Prescribing psychoactive drugs to addicts. $\mathrm{Br}$ Med $\mathcal{F} 1980$; 281 :497-8.

${ }^{13}$ Ghodse AH. Treatment of drug addiction in London. Lancet 1983; : 636-9.

${ }^{14}$ House of Commons. Official report (Hansard) 1982;March 18:1236, 174-5.

(Accepted 8 April 1983) 